\title{
Current Trends and Future Directions in the Study of Psychosocial Treatments for Pathological Gambling
}

\author{
David M. Ledgerwood and Nancy M. Petry \\ Department of Psychiatry, University of Connecticut Health Center
}

\begin{abstract}
Pathological gambling is a psychiatric disorder that has considerable public-health implications. Promising treatments for pathological gambling have been identified. However, most treatment research is limited by methodological problems that preclude drawing conclusions about treatment efficacy. We explore the empirical evidence for some currently practiced treatments for pathological gambling. We also discuss some of the challenges and future directions for research on how to treat the disorder.
\end{abstract}

KEYWORDS-pathological gambling; treatment; psychotherapy

Pathological gambling is an impulse-control disorder that results in disruptions of personal, family, and vocational activities (American Psychiatric Association, 2000). Pathological gamblers often have mental-health, legal, and financial problems as well. In North America, increasing opportunities to gamble in recent decades may have resulted in increases in the prevalence of pathological gambling. Estimates suggest that up to 5 million (1.6\%) Americans have met diagnostic criteria for this disorder at some point in their lifetimes (Shaffer, Hall, \& Vander Bilt, 1999).

Although pathological gambling is fairly prevalent, less is known about its treatment than about the treatment of other problems with similar prevalence rates, such as cocaine addiction or schizophrenia. Several challenges face researchers

Address correspondence to David M. Ledgerwood or Nancy M. Petry, Department of Psychiatry, University of Connecticut Health Center, 263 Farmington Ave., Farmington, CT 06030-3944. e-mail: ledgerwood@ psychiatry.uchc.edu or petry@psychiatry.uchc.edu. studying the treatment of pathological gambling. Because the disorder has only recently emerged as a public-health concern, the field must catch up to the research advances in other areas. Research on gambling treatment has been limited by methodological problems, and controlled clinical trials of psychotherapeutic and pharmacological approaches for pathological gambling were almost nonexistent until the late 1990s. In this article we discuss the current state of research on psychosocial treatments for pathological gambling. We also highlight issues that have implications for future research.

\section{GAMBLING TREATMENT}

Here we review a sample of the current research on psychosocial treatments for pathological gambling. These studies are further outlined in Table 1. Although this is not an exhaustive review, we made an effort to identify studies (when available) that used random assignment to treatment and long-term followups. The table indicates which studies were descriptive (i.e., did not use random assignment to treatments) and which used random assignment.

Gamblers Anonymous (GA)

GA is the most widely used treatment for pathological gambling. It is a 12-step, peer-support approach to gambling abstinence that was modeled after Alcoholics Anonymous. GA is based on a medical model of addiction that emphasizes a person's powerlessness over his or her gambling. Change comes through fellowship with other gamblers, believing that a higher power will restore healthy functioning, making a personal inventory of one's shortcomings, and making amends to people who have been harmed by one's gambling. GA holds meetings in all U.S. states and internationally. However, few studies have explored 
TABLE 1

A Sample of Studies of Psychosocial Treatments for Pathological Gambling

\begin{tabular}{|c|c|c|c|c|}
\hline Study & Treatment and comparison groups & Initial $N$ & Type of study & Outcomes \\
\hline \multicolumn{5}{|c|}{ Gamblers Anonymous (GA) } \\
\hline $\begin{array}{l}\text { Stewart \& } \\
\quad \text { Brown (1988) }\end{array}$ & $\begin{array}{l}\text { 12-step self-help group; no comparison } \\
\text { group. }\end{array}$ & 232 & Descriptive & $\begin{array}{l}\text { At } 1 \text { year following entry to group, gambling abstinence } \\
\text { was maintained by } 8 \% \text { of group members; at } 2 \text { years, } \\
\text { abstinence was maintained by } 7 \% \text { of group members. } \\
\text { Up to } 22 \% \text { dropped out after the 1st meeting; nearly } \\
70 \% \text { dropped out by their } 10 \text { th meeting. }\end{array}$ \\
\hline Petry (2003) & $\begin{array}{l}\text { Community-based gambling treatment plus } \\
\text { GA (54\%) vs. community-based treatment } \\
\text { alone. }\end{array}$ & 342 & Descriptive & $\begin{array}{l}\text { GA attendees were more likely to be abstinent from } \\
\text { gambling } 2 \text { months into treatment }(48 \%) \text {, compared } \\
\text { with patients who did not attend GA (36\%). GA } \\
\text { attendees also attended a greater proportion of their } \\
\text { professional therapy sessions. }\end{array}$ \\
\hline
\end{tabular}

Self-directed treatment

Hodgins, Currie, Self-help workbook alone vs. self-help \& el-Guebaly workbook plus one motivational interview (2001) vs. placement on a waiting list (control).
102 Random

(93) assignment
Self-help workbook plus motivational interview resulted in greater reductions in gambling than observed in either of the other two groups. Self-help workbook alone did not improve gambling relative to the waiting list.

Cognitive therapy and cognitive-behavioral therapy (CBT)

\begin{tabular}{|c|c|c|c|c|}
\hline $\begin{array}{l}\text { McConaghy, } \\
\text { Blaszczynski, } \\
\text { \& Frankova } \\
\text { (1991) }\end{array}$ & $\begin{array}{l}\text { CBT vs. behavioral treatment (aversion } \\
\text { therapy). Both treatments were } \\
\text { administered over a 5-day period while the } \\
\text { patients were hospitalized. }\end{array}$ & $\begin{array}{l}120 \\
(63)\end{array}$ & $\begin{array}{l}\text { 2- to 9-year } \\
\text { follow-up } \\
\text { following } \\
\text { random } \\
\text { assignment }\end{array}$ & $\begin{array}{l}\text { Up to } 79 \% \text { of patients who received CBT reported } \\
\text { abstinence or controlled gambling; } 53 \% \text { of the } \\
\text { patients who received behavioral treatment reported } \\
\text { abstinence or controlled gambling at the follow-up. }\end{array}$ \\
\hline $\begin{array}{l}\text { Echeburua, } \\
\text { Baez, \& } \\
\text { Fernandez- } \\
\text { Montalvo } \\
\text { (1996) }\end{array}$ & $\begin{array}{l}\text { Individual CBT vs. group cognitive therapy } \\
\text { vs. combined treatment vs. placement on } \\
\text { waiting list (control). CBT, cognitive } \\
\text { therapy, and the combined treatment } \\
\text { continued for } 6 \text { weeks. }\end{array}$ & $\begin{array}{l}64 \\
(50)\end{array}$ & $\begin{array}{l}\text { Random } \\
\text { assignment }\end{array}$ & $\begin{array}{l}\text { At } 6 \text { months, } 75 \%, 63 \%, 38 \% \text {, and } 25 \% \text { of the CBT, } \\
\text { cognitive therapy, combined therapy, and control } \\
\text { groups, respectively, successfully abstained from or } \\
\text { reduced gambling. At } 12 \text { months, } 69 \% \text { of CBT } \\
\text { patients were successful, compared with } 38 \% \text { of } \\
\text { cognitive-therapy and combined-treatment patients. }\end{array}$ \\
\hline $\begin{array}{l}\text { Sylvain, } \\
\text { Ladouceur, } \\
\text { \& Boisvert } \\
\text { (1997) }\end{array}$ & $\begin{array}{l}\text { Individual CBT (cognitive correction, } \\
\text { problem solving, social skills, and relapse } \\
\text { prevention) vs. placement on waiting list } \\
\text { (control). Therapy lasted } 60 \text { to } 90 \text { minutes, } \\
\text { twice weekly, up to a total of } 30 \text { hours of } \\
\text { treatment. }\end{array}$ & $\begin{array}{c}40 \\
(29)\end{array}$ & $\begin{array}{l}\text { Random } \\
\text { assignment }\end{array}$ & $\begin{array}{l}\text { In the treatment group, } 8 \text { of } 14 \text { patients improved by at } \\
\text { least } 50 \% \text { on measures of gambling severity, } \\
\text { perception of control, and desire to gamble; the gains } \\
\text { were maintained at follow-up. Only } 1 \text { of } 15 \text { patients } \\
\text { in control group made the same gains. }\end{array}$ \\
\hline $\begin{array}{l}\text { Ladouceur et al. } \\
\qquad(2001)\end{array}$ & $\begin{array}{l}\text { Individual cognitive therapy (cognitive } \\
\text { correction and relapse prevention) vs. } \\
\text { placement on a waiting list (control). } \\
\text { Therapy lased } 60 \text { minutes for a maximum } \\
\text { of } 20 \text { sessions. }\end{array}$ & $\begin{array}{c}88 \\
(64)\end{array}$ & $\begin{array}{l}\text { Random } \\
\text { assignment }\end{array}$ & $\begin{array}{l}\text { Nineteen of } 35 \text { treated patients, compared with } 2 \text { of } 29 \\
\text { patients in the control group, improved by at least } \\
50 \% \text { on measures of gambling severity, perception of } \\
\text { control over gambling, and desire to gamble. These } \\
\text { gains were maintained at follow-up. }\end{array}$ \\
\hline $\begin{array}{l}\text { Ladouceur et al. } \\
\qquad(2003)\end{array}$ & $\begin{array}{l}\text { Group cognitive therapy (cognitive } \\
\text { correction and relapse prevention) vs. } \\
\text { placement on a waiting list (control). } \\
\text { Treatment consisted of } 10 \text { weekly } \\
\text { sessions, each lasting } 120 \text { minutes. }\end{array}$ & $\begin{array}{c}71 \\
(61)\end{array}$ & $\begin{array}{l}\text { Random } \\
\text { assignment }\end{array}$ & $\begin{array}{l}\text { Among treated patients, } 88 \% \text { no longer met Diagnostic } \\
\text { and Statistical Manual of Mental Disorders criteria } \\
\text { for pathological gambling following treatment; } 20 \% \\
\text { of patients in the control group no longer met these } \\
\text { criteria. Treated patients were more likely to report } \\
\text { clinically significant declines in gambling than } \\
\text { control patients. }\end{array}$ \\
\hline $\begin{array}{c}\text { Petry et al. } \\
(2004)\end{array}$ & $\begin{array}{l}\text { GA referral vs. eight-chapter CBT workbook } \\
\text { and GA referral vs. eight-session } \\
\text { individual CBT and GA referral. CBT } \\
\text { sessions lasted } 50 \text { minutes. }\end{array}$ & $\begin{array}{c}231 \\
(217)\end{array}$ & $\begin{array}{l}\text { Random } \\
\text { assignment, } \\
\text { intent-to- } \\
\text { treat analysis }\end{array}$ & $\begin{array}{l}\text { CBT reduced gambling to a greater degree than GA } \\
\text { referral, and effects persisted throughout follow-up. } \\
\text { On some measures, individual CBT resulted in } \\
\text { greater improvements than the cognitive-behavioral } \\
\text { workbook. }\end{array}$ \\
\hline
\end{tabular}

Note. Initial $N$ is the number of patients randomly assigned to treatment or included in the study. The number of patients (if any) followed up after treatment

appears in parentheses.
40

88 assignment $50 \%$ on measures of gambling severity, perception of (ove gamble. These and Statistical Manual of Mental Disorders criteria of patients in the control group no longer met these The more likely to report

referral, and effects persisted throughout follow-up. greater improvements than the cognitive-behavioral workbook. 
the effectiveness of GA, and no controlled studies have been conducted.

In a study conducted by Stewart and Brown (1988), few people (8\%) who attended GA meetings remained abstinent for 1 year. Up to $22 \%$ of attendees dropped out after their first meeting, and only $30 \%$ attended for more than 10 meetings. Thus, GA may have only a limited impact on gamblers. More recently, however, Petry (2003) found that attendance at GA meetings may be associated with greater abstinence when individuals simultaneously receive professional treatment for pathological gambling, but no studies have examined the efficacy of GA as a stand-alone treatment. It is exceptionally difficult to study GA. Because GA is self-guided, and there are no specific guidelines concerning the number of meetings or duration of involvement in GA, the approach does not easily fit with the randomized design required to test efficacy (Stewart \& Brown, 1988).

\section{Self-Guided Approaches}

Other treatment approaches are more amenable to random assignment of patients to treatment groups. Hodgins, Currie, and el-Guebaly (2001) randomly assigned treatment-seeking problem gamblers to one of three groups: (a) self-help workbook (based on a cognitive-behavioral and relapse-prevention model); (b) workbook plus a motivational telephone interview; or (c) a no-treatment control (placement on a waiting list). The motivational interview focused on expressing empathy toward the client, exploration of discrepant thinking about addiction (i.e., addressing ambivalence about gambling), avoiding confrontation when the client was resistant to change, and encouraging self-efficacy (i.e., improving the client's belief that they can stop gambling). No significant differences in outcomes were found between the workbook and control groups. However, the participants who received the workbook and motivational interview reported less gambling than those who received only the workbook. The results of this initial study are promising, but additional research is needed to determine the appropriateness of self-guided interventions with different groups of gamblers, such as those with more severe gambling problems.

\section{Cognitive and Cognitive-Behavioral Treatments}

Treatments that, depending on their focus, are alternately called cognitive therapy and cognitive-behavioral therapy (CBT) are perhaps the most thoroughly studied interventions for pathological gambling to date. In more purely cognitive approaches, the therapist and patient identify cognitive distortions about the patient's gambling, such as the illusion of control over gambling and biased memories about past wins and losses, and attempt to modify these thoughts. Examples of cognitive distortions include, "I haven't won in the last 10 pulls, so I must be due," or "I'm really on a hot streak; I'm bound to win again." In CBT approaches, behavioral components may be added to reinforce non-gambling behaviors, encourage problem solving, improve social skills, and prevent relapse.

Some early studies compared CBT with behavioral techniques such as aversion therapy using electric shock paired with gambling stimuli (e.g., McConaghy, Blaszczynski, \& Frankova, 1991). More recently, a controlled study examined cognitive and CBT treatments in 64 gamblers (Echeburua, Baez, \& Fernandez-Montalvo, 1996). Patients were randomly assigned to (a) individual CBT (exposure to and control of gambling, and refusal-skill training), (b) group cognitive therapy (addressing cognitive distortions), (c) combined group and individual approaches, or (d) a waiting-list (control) condition. At the 6-month follow-up, the three treatment groups showed greater success (defined as two or fewer episodes of gambling) than the control group. Individual CBT was more effective in reducing gambling than the combined therapies and the control condition, but not significantly better than the group therapy at this follow-up. At the 12-month follow-up, people in the individual CBT group had better gambling outcomes than patients in the other two treatment groups.

Ladouceur's group has also studied cognitive therapy administered in individual (Ladouceur et al., 2001; Sylvain, Ladouceur, \& Boisvert, 1997) and group (Ladouceur et al., 2003) formats. Sylvain and her colleagues (1997) randomly assigned pathological gamblers to individual CBT or a waitinglist group. CBT addressed cognitive distortions, problem solving, social skills, and relapse prevention. Following treatment, CBT patients reported less gambling, fewer gambling-related problems, and greater perceived control over gambling than the waiting-list group.

Unfortunately, this study is weakened by its relatively small sample size. Lack of follow-up data is also a problem in most gambling-treatment studies. For example, in one investigation, nearly half of the 66 patients who received gambling treatment (including 59 patients randomized to receive treatment initially and 7 others who started in the control group but were offered treatment later) dropped out before completing it (Ladouceur et al., 2001), and dropouts were not interviewed at any of the follow-up assessments. Further, patients in the control group, who were put on a waiting list, were not studied at follow-up, because they were eventually referred for treatment once treatment was complete for patients randomized to the therapy condition. The study by Echeburua et al. (1996) had similar problems, including small sample size and no long-term followup of control patients.

\section{Our CBT Approach}

Our group has been studying a new CBT approach for several years. Briefly, our treatment model combines a cognitive model that addresses gambling-related thoughts and cognitive distortions with a behavioral perspective that suggests gambling is partially maintained by environmental contingencies. A central 
component of our approach is to have the patient restructure his or her environment in ways that make gambling less likely. Such restructuring may involve engaging in activities that the patient once considered enjoyable before developing a gambling problem or establishing new hobbies.

While patients restructure their environment during the course of treatment, they also gain new cognitive skills designed to reduce gambling. Patients are initially taught to identify gambling triggers and distorted cognitions about their gambling, such as ruminative thoughts about gambling, rationalizations that their gambling is not harmful, or the misremembering of past wins and losses. Therapists and patients use a technique called functional analysis, in which they identify antecedents (e.g., thoughts, triggers, urges) and consequences (positive and negative) of gambling. With this understanding, the client can begin to see how distorted cognitions contribute to gambling and can start to develop ways to cope with the urges and thoughts that lead to gambling behavior.

We have begun analyzing data from our first study of CBT treatment (Petry et al., 2004). In this study, 231 patients were randomly assigned to one of three groups: (a) GA referral, (b) GA referral plus an eight-chapter CBT workbook, or (c) GA referral plus eight sessions of individual CBT. Three of the four primary outcome measures showed better outcomes for the conditions including CBT than for GA referral alone, and many of these beneficial effects persisted throughout a 1-year followup period. Moreover, the individual-CBT condition reduced some aspects of gambling to a greater extent than the workbook condition. An intent-to-treat analysis was used (i.e., we included patients in our analyses even if they did not follow through with treatment), high follow-up rates were achieved, and patients' reports of participation in gambling activities were highly consistent with reports provided by other sources. We are currently conducting another study aimed at evaluating the efficacy of individual CBT compared with a psychoeducational intervention (i.e., providing information about gambling with supportive counseling).

\section{CHALLENGES AND FUTURE DIRECTIONS}

As researchers continue to refine their methods for studying the efficacy of psychosocial treatments for gambling, additional challenges are emerging. Some of the most important issues include how to conceptualize pathological gambling as a disorder, the possible impact of other psychiatric problems, the concurrent use of pharmacological treatments, and identifying factors that contribute to treatment failure and relapse.

\section{Conceptualization of Pathological Gambling}

Pathological gambling is classified as an impulse-control disorder, but it also has much in common with substance dependence, and many psychosocial treatments for pathological gambling are based on treatments for substance dependence (Petry, 2002). Addictive disorders are characterized by dependence symptoms such as tolerance and withdrawal. Impulse-control disorders, in contrast, are predominantly marked by an inability to resist harmful urges, impulses, or drives (American Psychiatric Association, APA, 2000). The causes and manifestations of addictive and impulse-control disorders are very different. Thus further research may examine the relationship between pathological gambling and addictive disorders, to determine whether they have similar causes and manifestations and respond to similar treatments.

\section{Co-occurring Psychiatric Disorders}

Co-occurring psychiatric and substance-use disorders are pervasive in pathological gambling. Pathological gambling is often accompanied by mood, anxiety, attention-deficit-hyperactivity, antisocial-personality, and substance-use disorders (APA, 2000). This fact raises several questions about treatment. For example, should treatments designed for pathological gambling also address co-occurring psychiatric problems? How does the presence of other disorders affect chances for treatment success? Unfortunately, no current studies address how co-occurring psychopathology may affect the outcomes of gambling treatment.

Depression or substance dependence, for example, may exacerbate a patient's gambling problems. A depressed person may use gambling to escape from painful emotions associated with psychiatric problems, whereas someone who is dependent on cocaine may enjoy the rush associated with gambling. If such additional issues are not considered during treatment, the pathological gambler may have difficulty abstaining from gambling or may cope with the unmet desire to gamble in ways that create or exacerbate other problems. Future studies of the role gambling plays in the lives of pathological gamblers may lead to a better understanding of different types of pathological gamblers and effective treatments for each type.

\section{Pharmacological Treatments}

Another issue that is pertinent to psychosocial treatment is the parallel development of pharmacological treatment approaches. Pharmacological treatments have demonstrated some initial promise in reducing gambling and gambling urges. As with psychotherapies, pharmacotherapies have been influenced by the development of medications to treat substance-use disorders (Petry, 2002). We (Petry, 2002) have noted that medications designed to reduce the reinforcing effects of gambling and those that are used to treat concomitant psychiatric problems may be most successful in reducing gambling. To date, no medication has been approved by the U.S. Food and Drug Administration for treating pathological gambling. Nevertheless, pharmacotherapy is an exciting line of gambling-treatment research; with further research, we may find that a combination of pharma- 
cological and psychosocial treatments prove more effective than either alone. Researchers continue to examine the efficacy of naltrexone (a medication typically used to reduce the reinforcing effects of alcohol and block the effects of heroin) and antidepressants for the treatment of gambling problems (see Grant \& Kim, 2002, for review). Future research will focus on establishing the efficacy of pharmacotherapeutic approaches to gambling treatment and may also examine the efficacy of combining psychotherapy and medication.

\section{Treatment Failure and Relapse}

Factors that lead to treatment failure and relapse in pathological gambling have rarely been studied. The presence of other psychopathology, gambling severity, and social support may be related to treatment outcomes. However, only a handful of studies have begun to explore these issues. In one recent review article, Daughters, Lejeuz, Lesieur, Strong, and Zvolensky (2003) described preliminary data that suggest lower distress tolerance may be associated with treatment failure. Such a finding may be consistent with the notion that people gamble to escape from painful emotions. If this relationship proves to be important, therapies that emphasize the development of coping skills may reduce treatment failure and relapse.

In another study, Leblond, Ladouceur, and Blaszczynski (2003) found that impulsivity was associated with treatment failure. Future interventions may focus on treatment techniques that help patients who are impulsive stay on target with recovery goals. Impulsive patients may benefit from CBT more than from other approaches, for example, because CBT offers a structured approach that addresses distorted thinking about gambling and emphasizes restructuring the environment to make gambling less accessible.

Repearch is needed to identify factors that contribute to relapse and treatment failure in patients with pathological gambling. Once these factors are identified, researchers may use this understanding to develop effective interventions for this disorder.

\section{Methodological Challenges}

Difficulties with methodology also continue to be of central importance in pathological-gambling treatment research. Few controlled studies have been conducted, and research to date is characterized by a number of methodological limitations. For example, most GA studies examine change in gambling in a treatment group without comparing that group with a control group. Most gambling-treatment studies that do have adequate controls are hindered by small sample sizes and lack of adequate follow-up. Finding and retaining pathological gamblers is a difficulty that has led to small treatment samples and problems interpreting follow-up results. A primary goal of future research will be to develop better ways of tracking and contacting gamblers for follow-up, including obtaining multiple contacts who may provide information on the patient if he or she cannot be contacted directly. Better follow-up data will improve understanding of gambling relapses and natural recovery processes.

Although most existing studies are limited, gambling research is currently moving toward greater use of controlled trials, manual-based psychotherapeutic approaches, and pharmacological treatments. Studies of cognitive, CBT, and motivational-interviewing approaches, in particular, have provided some promising data, and new studies will attempt to refine research methodology further.

\section{CONCLUSION}

Although recent research has demonstrated the promise of various treatments for pathological gambling, the field of gambling studies has not achieved a level of sophistication and rigorous standards that would enable claims to be made about the efficacy of gambling treatment. With a clearer focus on the issues highlighted in this article (e.g., relapse, co-occuring psychopathology), future studies will expand current knowledge about effective treatment for pathological gambling.

Despite the limitations of current research, we can speculate about what interventions might prove to be the most beneficial. Approaches that try to change cognitive distortions about gambling and rearrange the patient's environment to make gambling less likely appear to be useful, and they currently have the most empirical support. Initial studies exploring the use of motivational enhancement to improve a patient's willingness to take steps to reduce gambling are also promising. And structured clinical interventions such as CBT may prove to be even more effective when combined with the fellowship of GA or with medication. Further research will help clarify these issues and determine the best treatments for pathological gambling.

\section{Recommended Reading}

Petry, N.M., \& Armentano, C. (1999). Prevalence, assessment, and treatment of pathological gambling: A review. Psychiatric Services, $50,1021-1027$.

Petry, N.M., \& Roll, J.M. (2001). A behavioral approach to understanding and treating pathological gambling. Seminars in Clinical Neuropsychiatry, 6, 177-183.

Toneatto, T., \& Ladouceur, R. (2003). Treatment of pathological gambling: A critical review of the literature. Psychology of Addictive Behaviors, 17, 284-292.

Acknowledgments-Preparation of this report was supported in part by National Institutes of Health Grants R01-MH60417, R01-MH60417-suppl, R01-DA13444, R01-DA016855, P50AA03510, and P50-DA09241, and by the Patrick and Catherine Weldon Donaghue Medical Research Foundation. 


\section{REFERENCES}

American Psychiatric Association. (2000). Diagnostic and statistical manual of mental disorders (4th ed, text rev.). Washington, DC: Author.

Daughters, S.B., Lejeuz, C.W., Lesieur, H.R., Strong, D.R., \& Zvolensky, M.J. (2003). Towards a better understanding of gambling treatment failure: Implications of transitional research. Clinical Psychology Review, 23, 573-586.

Echeburua, E., Baez, C., \& Fernandez-Montalvo, J. (1996). Comparative effectiveness of three therapeutic modalities in the psychological treatment of pathological gambling: Long-term outcome. Behavioural and Cognitive Psychotherapy, 24, 51-72.

Grant, J.E., \& Kim, S.W. (2002). Pharmacotherapy of pathological gambling. Psychiatric Annals, 32, 186-191.

Hodgins, D.C., Currie, S.R., \& el-Guebaly, N. (2001). Motivational enhancement and self-help treatments for problem gambling. Journal of Consulting and Clinical Psychology, 69, 50-57.

Ladouceur, R., Sylvain, C., Boutin, C., Lachance, S., Doucet, C., \& Leblond, J. (2003). Group therapy for pathological gamblers: A cognitive approach. Behaviour Research and Therapy, 41, 587596.

Ladouceur, R., Sylvain, C., Boutin, C., Lachance, S., Doucet, C., Leblond, J., \& Jacques, C. (2001). Cognitive treatment of pathological gambling. Journal of Nervous and Mental Disease, 189, 774-780.
Leblond, J., Ladouceur, R., \& Blaszczynski, A. (2003). Which pathological gamblers will complete treatment? British Journal of Clinical Psychology, 42, 205-209.

McConaghy, N., Blaszczynski, A., \& Frankova, A. (1991). Comparison of imaginal desensitization with other behavioral treatments of pathological gambling: A two- to nine-year follow-up. British Journal of Psychiatry, 159, 390-393.

Petry, N.M. (2002). How treatments for pathological gambling can be informed by treatments of substance use disorders. Experimental and Clinical Psychopharmacology, 10, 184-192.

Petry, N.M. (2003). Patterns and correlates of Gamblers Anonymous attendance in pathological gamblers seeking professional treatment. Addictive Behaviors, 28, 1049-1062.

Petry, N.M., Ammerman, Y., Bohl, J., Doersch, A., Gay, H., Kadden, R., Molina, C., \& Steinberg, K. (2004). Cognitive-behavioral treatment for pathological gambling. Manuscript submitted for publication.

Shaffer, H.J., Hall, M.N., \& Vander Bilt, J. (1999). Estimating the prevalence of disordered gambling behavior in the United States and Canada: A research synthesis. American Journal of Public Health, 89, 1369-1376.

Stewart, R.M., \& Brown, R.I. (1988). An outcome study of Gamblers Anonymous. British Journal of Psychiatry, 152, 284-288.

Sylvain, C., Ladouceur, R., \& Boisvert, J.-M. (1997). Cognitive and behavioral treatment of pathological gambling: A controlled study. Journal of Consulting and Clinical Psychology, 65, 727732 . 